\title{
Determination of Catalytic Rate Constants towards Polymeric Conversion to Synthetic Oils: Bridging the Gap between Kinetics and Thermodynamics
}

\author{
Zharama M. Llarena \\ Gokongwei College of Engineering, De La Salle University, Manila, Philippines \\ Email: zharllarena21@yahoo.com.ph
}

How to cite this paper: Llarena, Z.M. (2017) Determination of Catalytic Rate Constants towards Polymeric Conversion to Synthetic Oils: Bridging the Gap between Kinetics and Thermodynamics. Journal of Materials Science and Chemical Engineering, 5, 1-11.

https://doi.org/10.4236/msce.2017.58001

Received: July 6, 2017

Accepted: August 8, 2017

Published: August 11, 2017

\begin{abstract}
Coal fly ash is being utilized as a recycling material for catalysis due to its aluminosilicate content. Catalytic conversion of polymeric wastes into synthetic gasoline and diesel through pyrolysis requires application of kinetic and thermodynamic principles. This study aimed to identify the catalytic rate constant necessary for rate law involved in reaction mechanisms and activation energy reduction needed for heat transfer rate. Stoichiometric application for balanced total series of elementary reactions is solved for the concentration determination of reactants and products. Unsteady-state in three dimensional directions of thermodynamics is derived for the determination of heat transfer rate, temperatures at any position in a sphere using Gurney and Lurie chart and center temperature in a sphere by Heisler chart. Application principles of rate law and Arrhenius equation can result to thermal conductivity as a function of activation energy leading to synthetic fuel production.
\end{abstract}

\section{Keywords}

Catalyst, Coal Fly Ash, Rate Law, Rate Constant, Thermal Conductivity

\section{Introduction}

Due to sudden global increase on the pressing energy request, enormous amounts of coal ash are being utilized every day from coal-fired power plants as its generated by-product. An estimation of 600 million tons of coal ash is being globally accountable to yield $80 \%$ fly ash. Twenty-five percent (25\%) of the generated fly ash is allotted to be applied as cement and concrete-related additives. 
The remaining seventy-five percent (75\%) is being dumped into landfill and lagoons resulting to soil and groundwater pollution. Since fly ash contains heavy metal pollutants, such as $\mathrm{As}, \mathrm{Pb}, \mathrm{Sn}$, and $\mathrm{Cd}$, remainder recycling by simple reclamation is essential to utilize its possible applications for environmental sustainability after removal of contaminants [1].

Traditional coal-fired power plants produce several waste streams in solid, liquid and flue gas phases. During 2011, the United States coal plants utilized and discharged several materials for energy production including 110 million tons of coal ash, almost 1 trillion gallons of water for processing, and emission of almost 1.6 billion tons of carbon dioxide $\left(\mathrm{CO}_{2}\right)$. In order to execute waste discharge reduction and its related detrimental effects to the environment, application for solid, liquid, and gaseous effluents has been treated with separated technologies, in spite of its expensive treatment most likely developed into a novel process that would regulate $\mathrm{CO}_{2}$ discharge [2].

Due to discharge of greenhouse gases vastly caused by human activities, there was a rapid growth in climate change after six (6) decades. Carbon dioxide $\left(\mathrm{CO}_{2}\right)$ is the predominant greenhouse gas in the atmosphere that has augmented its concentration to $39 \%$ last 2010 from preindustrial generation. Atmospheric carbon dioxide $\left(\mathrm{CO}_{2}\right)$ can lower its concentration by following the three main tactics: (i) reduction in the utilization of global energy; (ii) development of lowor non-carbon fuel; and (iii) sequestration of carbon dioxide $\left(\mathrm{CO}_{2}\right)$ from point of origins or from the atmospheric utilization of natural and engineering methods. Since coal-fired power plants emit carbon dioxide $\left(\mathrm{CO}_{2}\right)$ from its vast point of origin, carbon mitigation opts to be an essential need for carbon quarantine. Coal from fossil fuels generates majority of atmospheric carbon dioxide $\left(\mathrm{CO}_{2}\right)$ per unit of energy and its sole combustion is accountable to $20 \%$ of greenhouse gases being discharged worldwide. In spite of the attained developments in the growth and efficiency of energy from wind, biomass, nuclear and solar sources, global dependence on coal-based power is predicted to increase. In order to sustain chronic period of coal-based power industry, there is an important notice that requires coal-fired power plants for storage innovations that would lead to carbon capture development [3].

Investigations had urged on plastic improvement with novel recycling techniques due to continuous rise in polymeric consumption from several applications [4]. In the past decades, plastic consumption resulted to a sudden growth due to adoption of higher conditions of living and need of increasing human population throughout the world. Nowadays, modern community appears to be blended together with plastic materials and the society consuming polymers will have a hard time to live its absence since polymeric materials are regarded to have diverse utilizations in several fields such as medicine, household appliances, construction, packaging, automotive, electronics and aerospace parts [5].

Due to constant growth in polymer utilization leading to greater plastic yields dumped into waste stream, polymer recycling and reusing were encouraged to 
pursue and concentrate on reclamation and plastic recycling. There are several techniques for polymer reduction including reuse, mechanical recycling, and chemical recycling [5]:

Reuse: It is not globally performed as the general method of handling plastic products is to discard it subsequent to its earliest consumption. Although some milk and drinks containers are being utilized again with the same purpose, there is also marketplace reutilization in which several companies manufacture refill sachets for bottle re-consumption [5].

Mechanical recycling: It is also termed as physical recycling in which polymeric materials are grounded prior to being reprocessed for compounding in order to generate a novel element that may serve the same function or not [5].

Chemical recycling: The plastic material is transformed back into its oil/hydrocarbon constituent in instances where in polymers and monomers are utilized as raw components using appropriate chemical solvents for novel plastic production and applied to fuel company [5].

Coal Fly Ash (CFA) is a secondary result from solid fuels combustion consisting chiefly of non-flammable unburned carbons and inorganic entities. As an essential origin of energy with remarkable environmental and economic gains, these fine unburned carbons were used and recovered from CFA [6]. More determining attempts have been done recently in recycling fly ash such as utilization of almost $20 \%$ of the produced fly ash in generation of concrete. Other applications of fly ash involve soil amendment, road base construction, zeolite synthesis and filler in polymers. Investigation done by Ahmaruzzaman (2010) discussed the detailed properties of CFA and its several possible utilizations. Several studies are also done on fly ash applications which include various concepts on mine reclamation and soil amelioration, cenosphere and alumina recovery, heavy metal removal, wastewater treatment and biosequestraion [7].

Fuel for global electricity production broadly consumed coal as its major entity predicting to sustain its significance beyond 2035. During 2007, coal-fired electricity production resulted to $42 \%$ of the global supply of electricity, and through 2035, its contribution is expected to exist the same as before. Last 2010, electricity generation in Turkey was chiefly sustained from $45.9 \%$ natural gas, $25.3 \%$ coal, and $24.5 \%$ hydraulic resources, denoting that coal is regarded as the second most important electricity source [8].

Through coal firing, worldwide production of coal fly ash (CFA) is generated using facilities in pulverized coal combustion (PCC) [8]. The main chemical components of coal fly ash and its attributes are affected by various coal burned features such as anthracite, lignite, bituminous and sub-bituminous, combustion process, and cooling and heating regimes in the coal boiler [1]. Coal is one of the major important sources of electricity in Israel equivalent to $63 \%$ consumption in 2013 amounting to $13 \mathrm{Mt}$ of coal per annum. There are no coal resources in Israel and its utilization of bituminous coals are ocean imported and kept in huge piles of $60-150 \mathrm{kt}$ in open yards of 4 chief coal fired power plants. An es- 
timation of 1.3 Mt was generated in 2014 for annual production of the FA [9].

While the coal in a pulverized coal (PC) combustion performs two various conversion methods, like pyrolysis and char oxidation, transformation of minerals into ash occurs. The determination of carbon conversion into ash formation is termed as char oxidation that serves also as the rate limiting step. Subsequent to these transformation stages, ash with few amounts of residual carbon (UBC) has been produced. The porosity of coal structure great affect the ash formation and its properties [10].

Char with high porosity fragments leading to fine ash particles, while microporous chars yield in more compact and coarser ash particles. The particle size effect of PC maintains its complexity on ash formation. The mostly proven fact commonly predicted is that the bigger the particle coal size, the bigger the ash size, and most likely to result to BA formation, and if the coal size yields to finer particle formation, occurrence of FA is produced. In validation of Baxter's work which states the fact that big char particles have greater inclination to fragment into smaller particles. Several bituminous fly ash coals have particle size diameter (PSD) of commonly less than $75 \mu \mathrm{m}$ and its formation is most likely due to break down of big coal chars. For better consideration in accordance with the work of Sauter, clear knowledge both on FA production and its mean size both in PSD of pulverized coal (PC) and fly ash (FA) should be noted. Sauter has similar perspective with the research done by Seneca which entails that mean samples were only analyzed for fly ash exhibiting a modification ranging from 10 and $27 \mu \mathrm{m}[10]$.

Zeolites are synthesized by settlement of its structural constituents, namely, aluminum and silicon precursors. Several industrial waste materials even pure chemicals are appropriate to be of great potential for zeolite synthesis. Model development of zeolite chemistry for the acceptable utilization of industrial wastes can be promising tool for waste management and environmental protection, resulting to economical zeolite synthesis under the condition of waste material application. Coal fly ash is the most prolific secondary yield from coal-based thermal power plants. Coal fly ash can be easily transformed into zeolite because of its high silica-aluminum composition through hydrothermal treatment in a basic environment. This treatment method can result to the production of several zeolite types at varying parameters of temperature, basic concentrations of its reagent, solution to fly ash ratio and reaction time [11].

The mesoporous silica synthesis from coal fly ash has also gained its importance due to its high surface area, huge pore volume, and huge pore size going beyond the restrictions observed in microporous zeolites having pore sizes of less than $1.3 \mathrm{~nm}$. These mesoporous zeolites can be applied for carbon dioxide $\left(\mathrm{CO}_{2}\right)$ sequestration, adsorption and catalysis. Moreover, conversion of fly ash into sodium silicate through a liquid phase reaction with sodium hydroxide $(\mathrm{NaOH})$ can be utilized as a silica source exhibiting high surface area silica aerogels that can be applied in building insulation, catalysis, and adsorption via a 
surface modification route of wet gels and surrounding pressure for drying. Mixture of sodium silicate with acid-washed fly ash as an additive to generate adiabatic foams with adequate compression durability for insulation purposes [1]. This paper generally aimed to determine the catalytic rate constants required for the satisfaction of rules in kinetics for logical reaction mechanisms resulting to lowering the needed activation energy in thermodynamics.

\section{Methods}

Synthesis of mesoporous zeolites, its porosity and permeability will be determined by deriving an equation using Kozeny-Carman equation, shown below. From the equation, formula for permeability $(\mathrm{k})$ can be obtained. Moreover, average particle diameter $\left(D_{p}\right)$ can be computed through equation manipulation of hydraulic diameter $\left(D_{h}\right)$. Breakdown of equations necessary to solve for permeability is illustrated below:

$$
\mathcal{F}=150 \frac{V_{s} \mu(1-\varepsilon)^{2}}{D^{2}{ }_{p} \varepsilon^{3}} \frac{\Delta x}{\rho}
$$

Since,

$$
k=150 \frac{(1-\varepsilon)^{2}}{D^{2} \varepsilon^{3}}
$$

Hence,

$$
\mathcal{F}=\frac{V_{s}}{k} \frac{\mu}{\rho} \Delta x
$$

where,

$$
\begin{aligned}
D_{h}=4 r_{h} & =\frac{2}{3}\left(\frac{\varepsilon}{1-\varepsilon}\right) D_{p} \\
D_{p} & =\frac{3 D_{h}(1-\varepsilon)}{2 \varepsilon}
\end{aligned}
$$

Porosity of the catalyst can be calculated by obtaining the ratio between void volume and total system volume. Solid fraction can be obtained by subtraction of solved porosity from formula for solving porosity is shown below:

$$
\varepsilon=\frac{V_{f}}{V}
$$

where:

$$
\begin{aligned}
& V_{f}=\text { Void Volume } \\
& V=\text { Total System Volume }
\end{aligned}
$$

Also,

$$
\text { Solid Fraction }=1-\varepsilon
$$

Heat conduction is the mechanism behind the transfer of energy in the form of heat in motion between adjoining molecules. The rate of heat transfer $\left(q_{x}\right)$ is equivalent to the thermal conductivity $(\mathrm{k})$, expressed in negative sign to denote 
the conveyance of heat from higher to lower temperature, conducted in the $\mathrm{x}$ direction of its covered area, indicating the partial amount of change in the polymeric substances as it approaches its partial change from differential temperature with its equivalent time of its partial difference. The general formula for unsteady-state conduction equation is shown below:

$$
q_{x}=-k A \frac{\partial T}{\partial x}
$$

The pyrolysis of polymeric substances converts the plastic materials into synthetic fuels ( $\mathrm{z}$ ) using a zeolite as its biocatalyst and glycerol as its solvent with intermediate products formed, such as solid residue $(\mathrm{x})$ and waste gas $(\mathrm{y})$. The concept for the three (3) dimensional unsteady-state thermodynamics is shown in Figure 1.

Re-arrangement of the general equation in consideration with heat conduction in three (3) dimensions, namely, the partial change of polymeric materials into synthetic fuels $(\mathrm{x})$, waste gas $(\mathrm{y})$ and solid residue $(\mathrm{z})$. Second order rate of heat transfer describes the thermal diffusivity $(\alpha)$ of $\mathrm{Cr}$-aluminosilicate from partial heat change sequence in three dimensions $(\mathrm{x}, \mathrm{y}, \mathrm{z})$ in partial change of substance in varying series of time, plus the rate of heat generation $\left(\frac{q}{\rho c_{p}}\right)$ exhibited by the solvent, glycerol. The heat transfer rate for the production of synthetic fuels ( $\mathrm{x})$, waste gas (y) and solid residue ( $\mathrm{z})$ is expressed in the equation below:

$$
\frac{\partial T}{\partial t}=\alpha\left(\frac{\partial^{2} T}{\partial x^{2}}+\frac{\partial^{2} T}{\partial y^{2}}+\frac{\partial^{2} T}{\partial z^{2}}\right)+\frac{q}{\rho c_{p}}
$$

where:

$$
q_{x}=\text { rate of heat transfer }\left(q_{x}=-k A \frac{\partial T}{\partial x}\right)
$$

$$
A=\text { Area }
$$

$$
\alpha=\text { thermal diffusivity }\left(\frac{k}{\rho c_{p}}\right)
$$

$k=$ thermal conductivity

$$
\rho=\text { density }
$$$$
c_{p}=\text { heat capacity }
$$

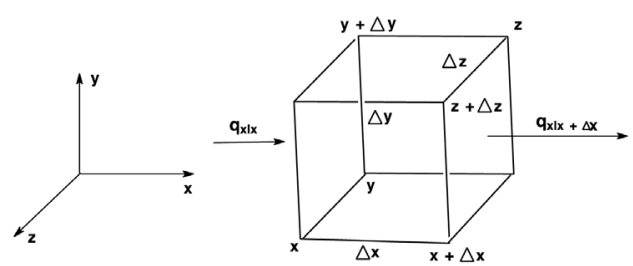

Figure 1. Unsteady-State Three Dimensional Heat Conduction Concept. 
Temperature can be determined by the ratio of the subtraction of the desired temperature and its temperatures at three (3) varying directions $(\mathrm{x}, \mathrm{y}, \mathrm{z})$, together with subtraction of the target temperature and the initial temperature in order to acquire the relative position at $y$-axis $(Y)$. For the radial direction, it can be solved by the product of thermal diffusivity $(\alpha)$ with time $(\mathrm{t})$ separated in respect to its radius. Tracking of center temperature can also be done in the same manner by using the center direction to obtain the temperature at the axial direction. Mathematical explanations are explained by the following equations needed for its determination within a dimensionless sphere.

Unsteady-State Heat Conduction in a Sphere:

$$
\begin{gathered}
Y_{x, y, z}=\left(Y_{x}\right)\left(Y_{y}\right)\left(Y_{z}\right)=\frac{T_{1}-T_{x, y, z}}{T_{1}-T_{0}} \\
X=\frac{\alpha t}{x^{2}} \\
n=\frac{x}{x_{1}} \\
m=\frac{k}{h x_{1}}
\end{gathered}
$$

Temperature at Center of a Sphere for Unsteady-State Heat Conduction:

$$
\begin{gathered}
Y_{0}=\frac{T_{1}-T}{T_{1}-T_{0}} \\
X=\frac{\alpha t}{x^{2}}
\end{gathered}
$$

where:

$x_{1}=$ radius

$h=$ heat transfer coeffient

$m=$ dimensionless ratio

$n=$ dimensionless ratio

\section{Discussion}

Glycerol upon thermal degradation is subjected to breakdown of molecules via deoxygenation and dehydration processes. Chain mechanisms involve reaction series undergoing initiation, propagation and termination steps. Initiation is the breakdown of the glycerol molecule which require activation energy for thermodynamic process needed to generate an exothermic yield. Radicals from the breakdown of glycerol will combine to form chain carriers in the propagation step which are vital for subsequent reactions to proceed. Termination step would combine deoxygenated and dehydrated molecules of glycerol to form condensed structure. Illustration of glycerol degradation is shown below:

Glycerol Degradation: 


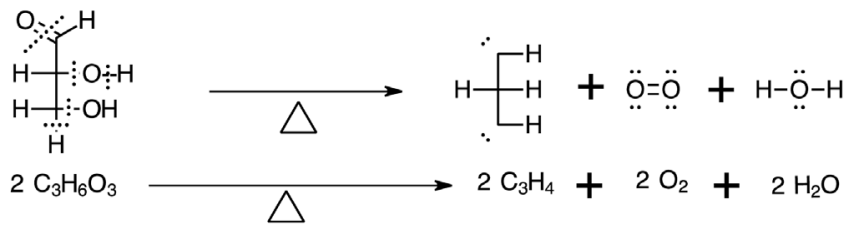

Initiation:

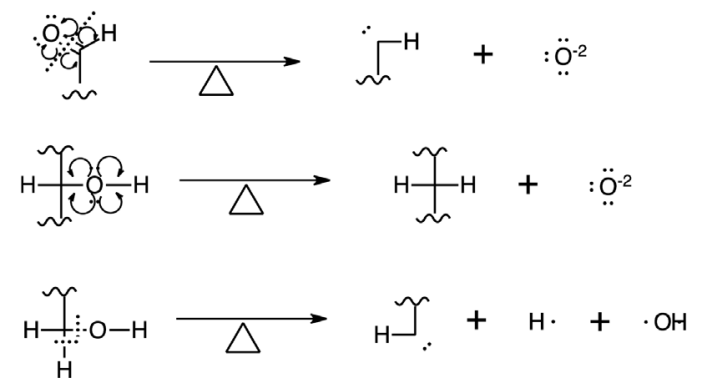

Propagation 1:

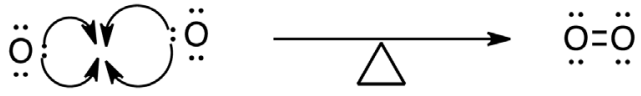

Propagation 2:

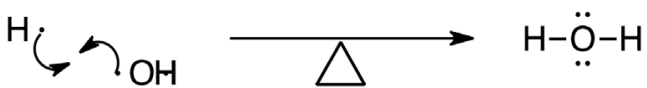

Termination:

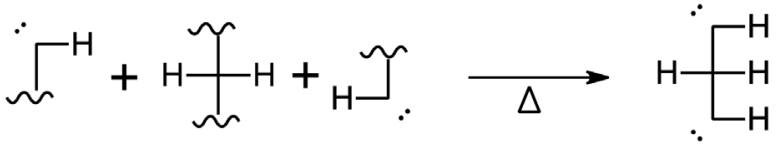

Plastic bottles contain high density polymer chains of linear structure which constitutes several linkages of polyethylene and polypropylene bonds. Subunits of polyethylene $(\mathrm{PE})$ chains are subjected to yield gasoline via SN2 reaction during combustion reaction wherein chain carrier, $\mathrm{O}_{2}$, attacks the $\mathrm{PE}$ chains leading to gasoline generation. Meanwhile, polypropylene (PP) subunits undergo the same reaction mechanism, thus, resulting to diesel production. Illustration of its reaction mechanism is shown below:

High Density Polymer General Structure (Linear):

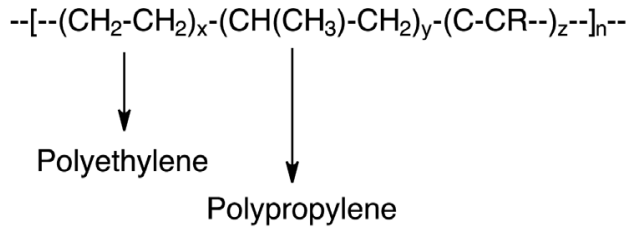


General Chain Reaction for Gasoline:

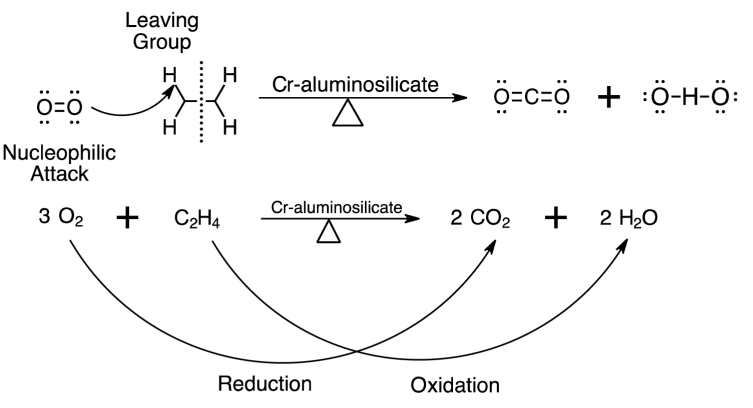

Initiation:

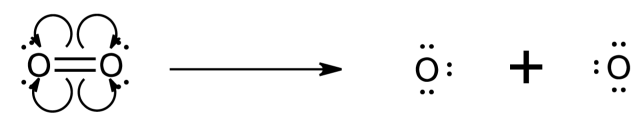

Propagation:

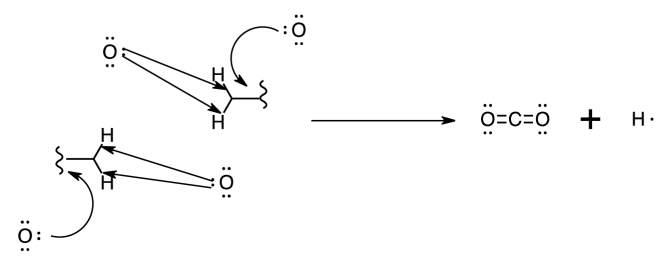

Termination:

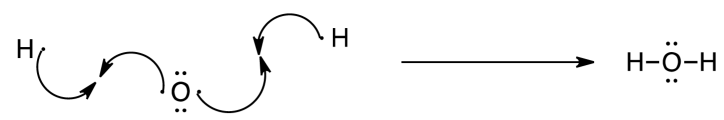

General Chain Reaction for Diesel:

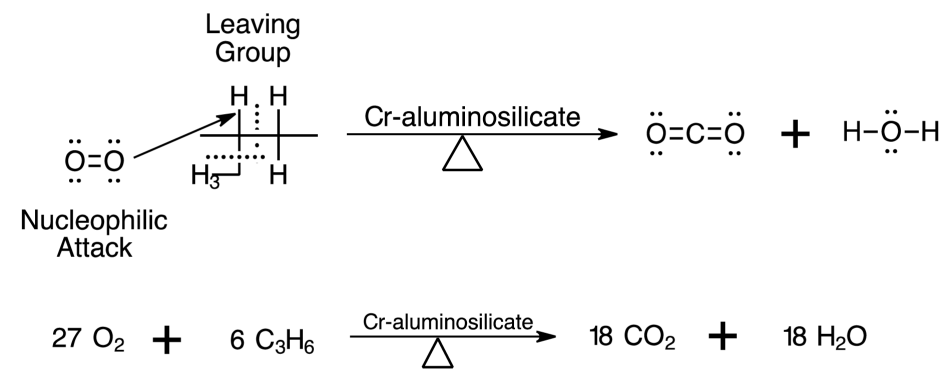

Initiation:

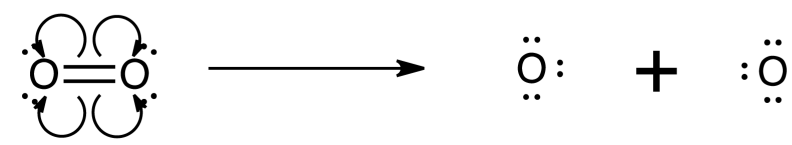

\section{Propagation 1:}




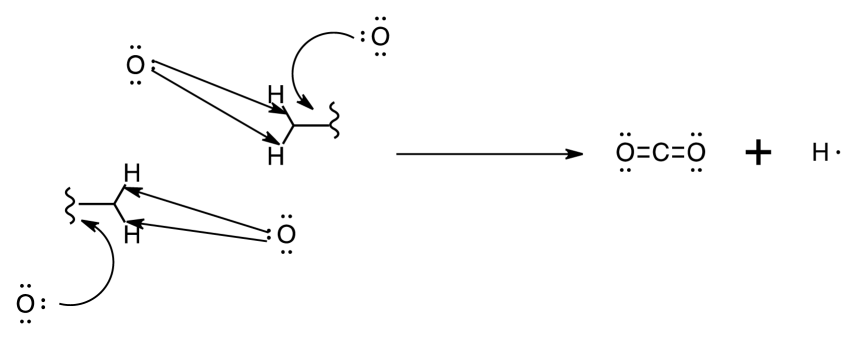

Propagation 2:

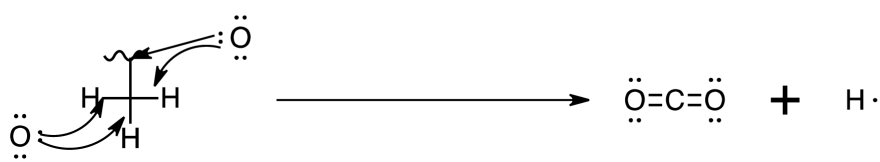

Termination:

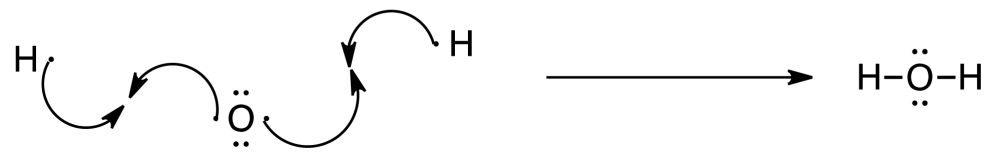

Rate law shows the relationship of concentration change in respect to varying change in time based on its molar relationship as a function of catalytic rate constant, leading to thermal conductivity as expressed according to Arrhenius equation following the unsteady state three dimensional thermodynamic principle for heat transfer. Rate expressions from chemical reactions are illustrated and expressed below:

$$
\begin{gathered}
a A+b B \rightarrow c C+d D \\
\text { rate }=-\frac{1}{a} \frac{\Delta[A]}{\Delta t}=-\frac{1}{b} \frac{\Delta[B]}{\Delta t}=\frac{1}{c} \frac{\Delta[C]}{\Delta t}=\frac{1}{d} \frac{\Delta[D]}{\Delta t} \\
\text { Rate }=k_{c}[\text { reactants }] \\
\text { Rate }=k_{c}[A]^{x}[B]^{y} \\
k_{c}=\frac{\text { Rate }}{[A]^{x}[B]^{y}}
\end{gathered}
$$

\section{Conclusion}

Waste to energy (WTE) technology is a popular tool to divert wastes and utilize it to produce energy as global consumption of fuels has increased and is projected to augment due to increasing population and worldwide industrialization is growing. Polymeric recycling via thermal degradation using zeolites as catalyst helps to increase the production of synthetic fuels for increasing energy demands. Thermal conductivity is a good analytical function to explain various phenomena in thermodynamics following established theories of rate law and 
Arrhenius equation.

\section{References}

[1] Lee, Y.R., Soe, J.T., Zhang, S., Ahn, J.W., Park, M.B. and Ahn, W.S. (2017) Synthesis of Nanoporous Materials via Recycling Coal Fly Ash and Other Solid Wastes: A Mini Review. Chemical Engineering Journal, 317, 821-843. https://doi.org/10.1016/j.cej.2017.02.124

[2] Lu, L., Fang, Y., Huang, Z., Huang, Y. and Ren, Z.J. (2016) Self-Sustaining Carbon Capture and Mineralization via Electrolytic Carbonation of Coal Fly Ash. Chemical Engineering Journal, 306, 330-335. https://doi.org/10.1016/j.cej.2016.07.060

[3] Ukwattage, N.L., Ranjith, P.G., Yellishetty, M., Bui, H.H. and Xu, T. (2015) A Laboratory-Scale Study of the Aqueous Mineral Carbonation of Coal Fly Ash for $\mathrm{CO}_{2}$ Sequestration. Journal of Cleaner Production, 103, 665-674. https://doi.org/10.1016/j.jclepro.2014.03.005

[4] Serranti, S., Luciani, V., Bonifazi, G., Hu, B. and Rem, P.C. (2015) An Innovative Recycling Process to Obtain Pure Polyethylene and Polypropylene from Household Waste. Waste Management, 35, 12-20. https://doi.org/10.1016/j.wasman.2014.10.017

[5] Hamad, K., Kaseem, M. and Deri, F. (2013) Recycling of Waste from Polymer Materials: An Overview of the Recent Works. Polymer Degradation and Stability, 98, 2801-2812. https://doi.org/10.1016/j.polymdegradstab.2013.09.025

[6] Zhou, F., Yan, C., Wang, H., Zhou, S. and Liang, H. (2017) The Result of Surfactants on Froth Flotation of Unburned Carbon from Coal Fly Ash. Fuel, 190, 182 188. https://doi.org/10.1016/j.fuel.2016.11.032

[7] Yao, Z.T., Ji, X.S., Sarker, P.K., Tang, J.H., Ge, L.Q., Xia, M.S. and Xi, Y.Q. (2015) A Comprehensive Review on the Applications of Coal Fly Ash. Earth-Science Reviews, 141, 105-121. https://doi.org/10.1016/j.earscirev.2014.11.016

[8] Bekat, T., Erdogan, M., Inal, F. and Genc, A. (2012) Prediction of the Bottom Ash Formed in a Coal Fired Power Plant Using Artificial Neural Networks. Energy, 45, 882-887. https://doi.org/10.1016/j.energy.2012.06.075

[9] Lieberman, R.N., Querol, X., Moreno, N., Mastai, Y. and Cohen, (H. 2016) Physical and Chemical Changes in Coal Fly Ash during Acidic or Neutral Wastes Treatment, and Its Effect on the Fixation Process. Fuel, 184, 69-80. https://doi.org/10.1016/j.fuel.2016.06.107

[10] Bilen, M. and Kizgut, S. (2016) Modeling of Unburned Carbon in Fly Ash and Importance of Size Parameters. Fuel Processing Technology, 143, 7-17. https://doi.org/10.1016/j.fuproc.2015.10.039

[11] Xiang, Y., Wang, L. and Jiao, Y. (2016) Ultrasound Strengthened Biodiesel Production from Waste Cooking Oil Using Modified Coal Fly Ash as Catalyst. Journal of Environmental Chemical Engineering, 4, 818-824.

https://doi.org/10.1016/j.jece.2015.12.031 
Submit or recommend next manuscript to SCIRP and we will provide best service for you:

Accepting pre-submission inquiries through Email, Facebook, LinkedIn, Twitter, etc. A wide selection of journals (inclusive of 9 subjects, more than 200 journals)

Providing 24-hour high-quality service

User-friendly online submission system

Fair and swift peer-review system

Efficient typesetting and proofreading procedure

Display of the result of downloads and visits, as well as the number of cited articles Maximum dissemination of your research work

Submit your manuscript at: http://papersubmission.scirp.org/

Or contact msce@scirp.org 